\title{
Comparison between calculated and billed building energy consumption values of schools and daycare centers
}

\author{
Annu Ruusala ${ }^{1}$, Anssi Laukkarinen ${ }^{1, *}$, and Juha Vinha ${ }^{1}$ \\ ${ }^{1}$ Building physics research group, Faculty of Built Environment, P.O. Box 600, FI-31014 Tampere \\ University, Finland
}

\begin{abstract}
In many countries, building regulations set requirements for energy efficiency, which must be fulfilled in order to have a building permit. Because the actual building does not yet exist, the calculations are done in the early design phase with approximate input data. This paper presents results from dynamic whole-building simulations and compares the results to monthly calculation results, billed energy consumption and to a small number of central building energy efficiency parameters. According to the results, using a more sophisticated calculation tool does not necessarily improve the accuracy of the calculation results, if the capabilities of the tool are not properly utilised. Although there was a clear difference between the calculated and billed values, lower calculated energy consumption did correlate with lower billed values. Besides the need for extra effort to ensure accurate input data in general, input values related to infiltration and ventilation should be evaluated especially carefully.
\end{abstract}

\section{Introduction}

The energy efficiency of buildings is a large area, of which one important part is the accuracy of numerical predictions compared to the realised values. Ideally, the difference between calculated and realised building energy consumption should be small, so that building designers and developers could make well-informed decisions between different design options and eventually ensure that the building functions as planned.

The differences between calculated and measured building energy consumption have been studied from multiple perspectives in the existing literature. The term "Energy performance gap" is used to refer the general situation, when there is a difference between calculated and measured energy consumption values. This can occur due to matters e.g. in the building envelope, HVAC system, building use and/or in the physical models or calculation tools [1-3]. Even if the design targets have been reached, a phenomenon called the "rebound effect" can occur, which refers to an unplanned improvement in the service level (e.g. thermal comfort) and subsequently higher energy consumption after energy efficiency measures [4]. On the other hand, the "prebound effect" might be present, which

* Corresponding author: anssi.laukkarinen@tuni.fi 
is used to describe the lower-than-calculated energy consumption of old buildings [5]. With sufficient effort, it is possible to get a good match between the calculated and measured energy consumption values [6-8].

In Ruusala et al. (2018) [9] the billed energy consumption of eighteen Finnish schools and daycare centers were calculated with a monthly quasi-steady-state method [10-11], which is similar to the method presented in ISO 13790 [12]. The building use was described according to the Finnish regulatory building permit calculations, which is referred to as the standardised use. According to the results, the billed heating energy consumption (mainly district heating) was 51 (6...142) \% higher (mean, 5 and $95 \%$ percentiles) and electricity consumption $17(-3 \ldots 61) \%$ higher than the calculated values (in $\left.\mathrm{kWh} /\left(\mathrm{m}^{2} \mathrm{a}\right)\right)$. The large average difference in the heating consumption questioned the use of the monthly method, although it fulfils the regulatory requirements.

The current work is a continuation to the results presented in Ruusala et al. (2018) [9] and most of the details related to input data and methods are the same than in that publication. This paper presents the results for the same case buildings and input data, but calculated with a dynamic whole-building simulation tool. Besides the more detailed calculations, also the impact of a small number of explanatory indicators are evaluated to see how they can be used to predict the billed energy consumption.

\section{Methods}

To compare the billed building energy consumption with calculated values, first the total billed building heating energy and electricity consumption data was gathered from the Finnish cities of Tampere, Helsinki and Oulu from years 2014 and 2015. The heating energy consumption was normalised to the conditions of the test reference year "Vantaa 2012 " with the use of heating degree days. That specific year is used for regulatory building energy consumption and indoor air condition calculations in Finland. Also, other available input data was gathered from building design documents, such as areas and information about building envelope and HVAC systems. For input data related to building use, such as indoor air temperature, use of electrical appliances, ventilation rate and indoor heat loads, the regulatory "standardised use" was used. Although this can be seen only as an approximation to the actual use, more detailed information was also not available in the existing design documentation.

After gathering the input data, case buildings $(n=18)$ were selected for which there was sufficient information available to compare the calculated and billed values and which were considered to be representative for typical Finnish schools and daycare centers. The buildings were taken into use during 2005-2013. The calculations were done with the monthly method and with the commonly used dynamic whole-building simulation software IDA Indoor Climate and Energy, version 4.7.1 [13]. The monthly calculation method is presented in $[10,11]$ and those results have been previously reported in [9], along with more detailed information on the input data and calculation method related to this study also.

To study the calculation results further a multiple linear regression model was fit to the data with a small number of explanatory variables. The statistical calculations were done using the statsmodels package in the Python-environment [14]. To avoid numerical problems due to high condition number of the data matrix, all the explanatory and outcome variables were first standardised by subtracting their mean and then dividing by the standard

deviation. 


\section{Results}

The comparison of the two regulatory calculation methods and billed values for heating energy consumption are presented in Figure 1.

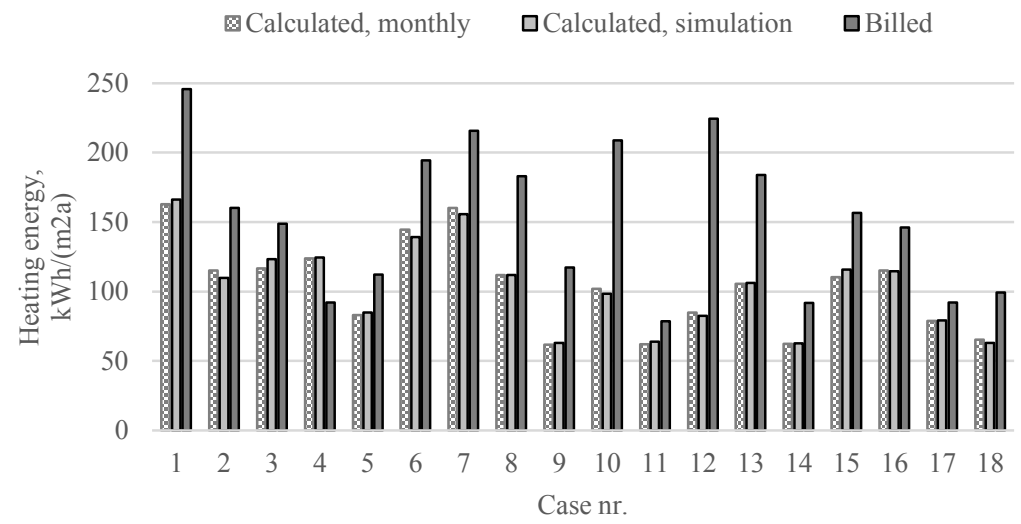

Fig. 1. Building energy consumption calculated with both the monthly calculation method and simulations, and the billed building energy consumption. The differences between calculations and billed values were bigger than the differences between the two calculation methods when using the regulatory input data.

The calculated values of yearly energy consumption were very close to each other with the two different calculation methods $\left(\mathrm{R}^{2} \geq 0.99\right.$ for heating energy and electricity). At the same time, the difference between the calculated and billed values was much bigger, taking also into account the results from dynamic simulations. This means that using a more sophisticated calculation tool does not necessarily improve the accuracy of the calculations compared to billed values, if the possibilities of the tool are not properly utilised.

Figure 2 shows a scatter diagram of the correlation between the billed and simulated values, including both heating energy and electricity consumption. Lower calculated values correlated with lower billed values, so although there was a clear difference between the billed and calculated values, the ranking of different buildings in terms of delivered energy remained the same on average. This means that the current regulatory calculations are better suited for comparative calculations (on average) than for calculating the exact energy consumption.

Based on Figure 2, the calculated and billed electricity consumption matched each other at $106 \mathrm{kWh} /\left(\mathrm{m}^{2} \mathrm{a}\right)$, which is at the high end of the billed values. For all the other electricity consumption values in the sample, both the absolute and relative difference increased when moving towards buildings with lower consumption. For heating energy consumption, the absolute difference decreased when moving towards buildings with lower heating energy consumption, but also there the relative difference increased. 


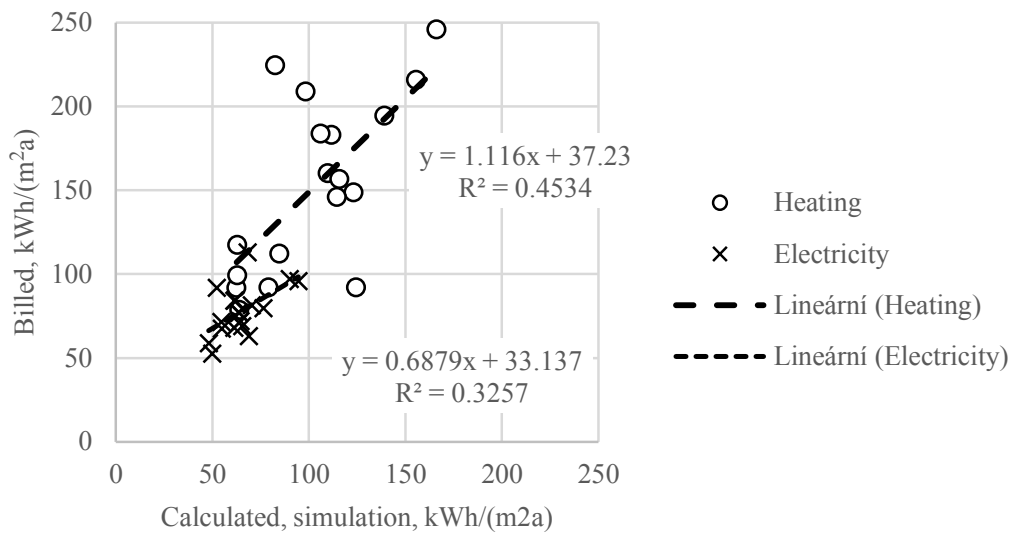

Fig. 2. Correlation between the calculated and billed yearly heating energy and electricity consumption. Lower calculated values correlate with lower billed values, but the relative error between the two increases when moving towards lower energy consumption.

In the whole sample, the mean and standard deviation were 103.6 and $31.7 \mathrm{kWh} /\left(\mathrm{m}^{2} \mathrm{a}\right)$ for the simulated heating energy consumption; 152.8 and $52.6 \mathrm{kWh} /\left(\mathrm{m}^{2} \mathrm{a}\right)$ for the billed heating energy consumption; 65.1 and $12.4 \mathrm{kWh} /\left(\mathrm{m}^{2} \mathrm{a}\right)$ for the simulated electricity consumption and 77.9 and $14.9 \mathrm{kWh} /\left(\mathrm{m}^{2} \mathrm{a}\right)$ for the billed electricity consumption. These values were used to standardise the energy consumption values of a multiple regression model. The regression model parameters, their mean and standard deviation, the coefficients and their $p$-values and the model $\mathrm{R}^{2}$-values are presented in Table 1.

Table 1. OLS model parameters, mean and standard deviation for standardising the input data, calculated model coefficients, $\mathrm{p}$-values and the regression model $\mathrm{R}^{2}$-values. $(*)$ means that the coefficient is significantly different from zero $(\mathrm{p}<0.05) . \mathrm{n}=18$.

\begin{tabular}{|c|c|c|c|c|c|}
\hline \multirow[b]{2}{*}{ Parameter } & \multirow[b]{2}{*}{$\begin{array}{c}\text { mean, } \\
\text { std }\end{array}$} & \multicolumn{2}{|c|}{ Simulated values } & \multicolumn{2}{|c|}{ Billed values } \\
\hline & & Heating & Electricity & Heating & Electricity \\
\hline $\begin{array}{l}\text { Floor area, } \\
\mathrm{m}^{2}\end{array}$ & $\begin{array}{l}2430 \\
2020\end{array}$ & $\begin{array}{l}-0.2697 \\
0.022(*)\end{array}$ & $\begin{array}{c}-0.3698 \\
0.424\end{array}$ & $\begin{array}{c}-0.1783 \\
0.604\end{array}$ & $\begin{array}{c}-0.3607 \\
0.316\end{array}$ \\
\hline $\begin{array}{l}\text { Shape factor, } \\
\mathrm{m}^{2} \text {-envelope } / \mathrm{m}^{2} \text {-floor }\end{array}$ & $\begin{array}{l}2.37 \\
0.456\end{array}$ & $\begin{array}{c}0.3277 \\
0.003(*)\end{array}$ & $\begin{array}{c}0.1663 \\
0.671\end{array}$ & $\begin{array}{l}0.3310 \\
0.27\end{array}$ & $\begin{array}{c}0.5254 \\
0.100\end{array}$ \\
\hline $\begin{array}{l}\text { Average envelope U-value, } \\
\qquad \mathrm{W} /\left(\mathrm{m}^{2} \mathrm{~K}\right)\end{array}$ & $\begin{array}{l}0.225 \\
0.0426\end{array}$ & $\begin{array}{c}0.4426 \\
0.0(*)\end{array}$ & $\begin{array}{c}0.0072 \\
0.981\end{array}$ & $\begin{array}{c}0.4506 \\
0.068\end{array}$ & $\begin{array}{c}-0.0427 \\
0.856\end{array}$ \\
\hline $\begin{array}{l}\text { Typical infiltration rate, } \\
\mathrm{m}^{3} /\left(\mathrm{m}^{2} \text {-envelope, } \mathrm{h}\right)\end{array}$ & $\begin{array}{l}0.115 \\
0.0642\end{array}$ & $\begin{array}{c}0.3347 \\
0.001(*)\end{array}$ & $\begin{array}{c}0.3900 \\
0.294\end{array}$ & $\begin{array}{c}-0.0121 \\
0.964\end{array}$ & $\begin{array}{c}0.4491 \\
0.128\end{array}$ \\
\hline $\begin{array}{c}\text { Annual ventilation heat recovery } \\
\text { efficiency, } \%\end{array}$ & $\begin{array}{l}66.9 \\
9.04\end{array}$ & $\begin{array}{c}-0.4572 \\
0.0(*)\end{array}$ & $\begin{array}{c}-0.1163 \\
0.676\end{array}$ & $\begin{array}{c}-0.2656 \\
0.217\end{array}$ & $\begin{array}{c}0.0373 \\
0.862\end{array}$ \\
\hline $\begin{array}{c}\mathrm{R}^{2} \\
\mathrm{R}^{2} \text { adjusted }\end{array}$ & & $\begin{array}{l}0.962 \\
0.946\end{array}$ & $\begin{array}{l}0.271 \\
-0.032\end{array}$ & $\begin{array}{c}0.590 \\
0.419\end{array}$ & $\begin{array}{c}0.566 \\
0.385\end{array}$ \\
\hline
\end{tabular}


An interesting result from Table 1 is that the used predictors had much more clear correlation with the simulated heating energy consumption values, than with the corresponding billed values. Although all the predictors were statistically significant for the simulated heating energy consumption, none of them was that for the billed heating energy consumption. Despite the relative complexity of the whole-building simulation model, it is still a simplification compared to the actual building.

The coefficient values in Table 1 had similar values in many cases, but differences occurred also. In heating energy consumption, the biggest differences were in the impact of air infiltration and somewhat also in the annual heat recovery efficiency, which is also related to airflows and ventilation. The regression coefficients were bigger for those two cases when looking at the simulated cases, and smaller for the billed cases. To reduce the differences between the calculated and billed values, the behaviour of air flows and the functioning of the ventilation system could be one preferred place to conduct further evaluations.

The model parameters and outputs were standardised, but the interpretation of the calculated coefficients is still not straightforward. The interpretation depends for example on the range of used values, interaction of the parameters in the regression equation, existence of other underlying variables (e.g. instrumental variables) and of the fact that the parameters in Table 1 are just a small number of all the influencing factors related to building energy consumption. Taking these into account, the strongest correlation (largest coefficients) to billed heating energy consumption was with the average envelope U-value and the building shape factor. These should be interpreted as a correlation and not as a direct cause-and-effect system. A more reliable prediction of heat losses through the building envelope could however be an advantage to structural energy efficiency measures, if the uncertainties reaching low ventilation heat losses are high.

The p-values related to electricity consumption were high in both cases of simulated and billed energy consumption values. It seems that the used parameters were not able to capture statistically significant changes related to those variables. One explanation of this could be that most of electricity consumption is related to user appliances and continuously running HVAC systems, in which case there is no direct link between the used parameters and the building use in yearly level. Lower electricity consumption values and standard deviation compared to heating energy makes the prediction a bit easier, but because the inaccuracies in predicting electricity consumption are projected to increase (Figure 2), better understanding of the electricity consumption in schools and daycare centers would be needed.

\section{Conclusions}

This paper presented the results from regulatory building energy consumption calculations with a dynamic whole-building simulation tool and compared those results to monthly calculation results, billed energy consumption values and simple building design parameters.

As a conclusion, changing from monthly calculation method to dynamic simulation did not improve the accuracy of regulatory calculation results compared to billed values. The differences between the calculated and billed values were considerably bigger, than the differences between the two calculation methods. Because dynamic simulations can be used to achieve a good accuracy compared to measured values, the primary reason for differences between the calculated and billed values is considered to be in the accuracy of the input data.

Lower calculated energy consumption values did correlate with lower billed values, but the relative difference between the calculated and billed values increased when moving 
towards lower energy consumption. For electricity consumption the difference increased also in terms of absolute values (in $\mathrm{kWh} /\left(\mathrm{m}^{2} \mathrm{a}\right)$ ). These results mean that the regulatory building permit calculations with standard use should be done only for comparison purposes. Other evaluations, such as evaluating indoor air conditions, dimensioning HVAC system and life cycle cost optimisation should be done with as accurate input data as possible.

The regression studies showed much clearer correlation between the explanatory parameters with calculated heating energy consumption values, than with billed values. When conducting calculations for building design, this should be taken into account by incorporating suitable reference cases, sensitivity studies and/or other more sophisticated methods. The biggest differences in the regression results between calculated and billed values were related to infiltration and heat recovery efficiency (compared to building size, shape and average envelope U-value) and are recommended to check properly before running calculations.

\section{References}

1. M. Deurinck, Energy savings in the residential building sector. An assessment on stochastic modelling. $\mathrm{PhD}$ thesis, KU Leuven. 218 p. (2015)

2. S. Roels (ed.), Reliable Building Energy Performance Characterisation Based on Full Scale Dynamic Measurements (Annex 58). Project Summary Report, 18 p. (2017)

3. K. Gram-Hansen, S. Georg, Energy performance gaps: promises, people, practices. Build. Res. Inf., 46:1, pp. 1-9. (2018)

4. R. Galvin, Making the 'rebound effect' more useful for performance evaluation of thermal retrofits of existing homes: Defining the 'energy savings deficit' and the 'energy performance gap'. Energy and Buildings 69, pp. 515-524. (2014)

5. M. Sunikka-Blank, R. Galvin, Introducing the prebound effect: the gap between performance and actual energy consumption. Build. Res. Inf. 40 (3), 260-273. (2012)

6. A. Molin, P. Rohdin, B. Moshfegh, Investigation of energy performance of newly built low-energy buildings in Sweden. Energy Build. 40, pp. 2822-2831. (2011)

7. A.C. Menezes, A. Cripps, D. Bouchlagmen, R. Buswell, Predicted vs. actual energy performance of non-domestic buildings: Using post-occupancy evaluation data to reduce the performance gap. Appl. Energ. 97, pp. 355-364. (2012)

8. T. Hong, J. Langevin,K. Sun, Building simulation: Ten challenges. Build. Simul. 11, pp. 871-898. (2018)

9. A. Ruusala, A. Laukkarinen, J. Vinha, Energy consumption of Finnish schools and daycare centers and the correlation to regulatory building permit values, Energ. Policy, 119, pp. 183-195. (2018)

10. Ministry of the Environment (2012a) 2/11 Decree of the Ministry of the Environment on the Energy Performance of New Buildings. (RakMK D3-2012, 35 p., in Finnish)

11. Ministry of the Environment (2012b) The Calculation of Building Energy Consumption and Heating Power Need. Guidelines. (RakMK D5-2012, 74 p., in Finnish)

12. SFS-EN ISO 13790 Energy performance of buildings. Calculation of energy use for space heating and cooling. Finnish Standards Association SFS, Helsinki, Finland. 162 p. (2008)

13. EQUA. https://www.equa.se/en/, last visited 28 Feb 2019.

14. S. Seabold, J. Perktold, Statsmodels: Econometric and statistical modeling with python. Proceedings of the 9th Python in Science Conference. (2010) 